Bernier, A., McMahon, C., \& Perrier, R. (2017). Maternal mind-mindedness and children's school readiness: A longitudinal study of developmental processes. Developmental Psychology, $53,210-221$. 


\begin{abstract}
This study aimed to test a five-wave sequential mediation model linking maternal mindmindedness during infancy to children's school readiness in kindergarten through a serial mediation involving child language and effortful control in toddlerhood and the preschool years. Among a sample of 204 mother-child dyads, we assessed maternal mind-mindedness when children were aged 1 year, child expressive vocabulary at age 2, effortful control at ages 3 and 4, and finally cognitive school readiness in kindergarten. The results corroborated the model, suggesting that the prospective association between early mind-mindedness and later cognitive school readiness was entirely mediated by the proposed sequence of mediators, all of which were necessary to account for this longitudinal association. These findings suggest that the potential of parental mind-mindedness to support children's cognitive development may have been underestimated, and that its putative positive influence may take the form of a developmental cascade unfolding during the preschool years and entailing the acquisition of basic skills that serve as building blocks for further learning and development.
\end{abstract}

Keywords: school readiness, mind-mindedness, serial mediation, language, effortful control. 


\section{Maternal mind-mindedness and children's school readiness: A longitudinal study of developmental processes.}

One of the most significant developmental milestones of early childhood is school entry, which involves numerous behavioral, social, and intellectual challenges that children must handle simultaneously (Sameroff \& Haith, 1996). Research shows that children vary widely in their adaptation to school entry, and these differences have lasting and significant consequences for academic, social, and behavioral outcomes in childhood (Ladd, 2004) and adolescence (Schofield, Bierman, Heinrichs, \& Nix, 2008). Consequently, it is imperative to explain why some children arrive in school better prepared than others.

One of the most useful concepts in this regard is school readiness. Although the definitions of school readiness vary, the general consensus is that this notion refers to the set of skills and knowledge components that are necessary to respond adequately to school demands (Carlton \& Winsler, 1999; Scarpati \& Silver, 1999). In particular, there is concern that children who lack pre-academic knowledge, that is, the basic knowledge that the early school curriculum assumes and builds on, may experience increasingly greater difficulty keeping up as the learning demands accumulate (Forget-Dubois et al., 2009), and thus gradually fall further behind their peers with more solid foundations. In fact, although social and emotional skills are important at school entry (Blair \& Raver, 2015), pre-academic knowledge is considered an especially salient component of school readiness because it is a substantially superior predictor of later academic achievement (Davies, Janus, Duku, \& Gaskin, 2015; Duncan et al., 2007).

Accordingly, measures intended to assess the knowledge and cognitive skills essential for success in the early primary grades (e.g., recognition of letters and numbers, knowledge of colors and shapes) have been developed, for instance the Lollipop test (Chew \& Morris, 1984) and the 
Metropolitan Readiness Tests (Nurss \& McGauvran, 1995). Such measures of cognitive school readiness have enabled the prediction of children's academic achievement throughout the early school years up to Grades 4 (Chew \& Morris, 1989; Kurdek \& Sinclair, 2001) and 5 (Kurdek \& Sinclair, 2000), with meta-analytic estimates of predictive relations as high as .50 in some cases (La Paro \& Pianta, 2000). Further, these predictions are not confounded by intellectual ability: Lemelin et al. (2007) reported that cognitive school readiness as assessed by the Lollipop at 5 years explained $20 \%$ of the variance in teacher-reported academic achievement two years later, after accounting for the contribution of general cognitive ability. Overall, research compellingly shows that entering school "ready to learn" (Connell \& Prinz, 2002) is a critical step toward early school success, and thus that identifying factors that promote cognitive school readiness should be given high priority (Lemelin et al., 2007).

One of the most promising factors identified thus far is parenting. Indeed, the quality of early parenting not only predicts children's school readiness (NICHD Early Child Care Research Network [ECCRN], 2003), but also accounts for the association between school readiness and more distal family factors, such as income or family composition (Mistry, Benner, Biesanz, Clark, \& Howes, 2010). Furthermore, studies show that intervention programs that effectively promote school readiness among at-risk children (e.g., Head Start) do so partly through their positive impact on parenting behavior (e.g., Parker, Boak, Griffin, Ripple, \& Peay, 1999). Especially convincing evidence for the role of parenting was provided by a study that found that maternal emotional support during a problem-solving task at age 3 predicted pre-academic skills at age 4, controlling for pre-academic skills at age 3 and general quality of the home learning environment (Leerkes, Blankson, O’Brien, Calkins, \& Marcovitch, 2011). Although this study provides quite a stringent test of the specific role of parenting in school readiness, its authors 
acknowledged that their parenting measure did not sufficiently tap into maternal verbal behavior, which has been found to be predictive of subsequent academic skills (Hubbs-Tait, Culp, Culp, \& Miller, 2002). Indeed, given the well-documented role of maternal verbal input in young children's cognitive development (e.g., Hoff \& Naigles, 2002), the verbal aspect of maternal behavior may be especially salient to the development of school readiness.

One aspect of maternal verbal behavior that is receiving increased attention is mindmindedness, defined as mothers' proclivity to attribute mental states to their infants (Meins, 1997), in other words to "treat their infant as an individual with a mind" (Meins, Fernyhough, Fradley, \& Tucker, 2001, p. 638). Mind-mindedness is an inherently verbal behavior, in that it is manifested by parental comments on infants' mental activity during parent-infant interactions (e.g, "You're thinking about which toy you want to play with next"). Meins (1997) proposed that caregivers who are oriented to their infants' mental states have the capacity to recognize infants' cognitive potential, correctly identify their zone of proximal development, and consequently provide appropriate developmental challenges to maximize their learning opportunities. Accordingly, mind-mindedness could have a direct positive impact on children's acquisition of pre-academic skills, and thus on school readiness.

Mind-mindedness could also play an indirect role by supporting the development of intermediate skills that in turn promote school readiness. Indeed, toddlerhood and the preschool years provide young children with countless opportunities to acquire basic skills that serve as building blocks for further learning (Merz et al., 2014). Two of the most widely studied developmental achievements of the toddlerhood and preschool periods are the development of language (Ganger \& Brent, 2004) and the emergence of children' capacity to inhibit impulsive responses (often called inhibitory control, voluntary control, or effortful control, e.g., Eisenberg 
\& Spinrad, 2004; Kochanska, Murray, \& Harlan, 2000). Both have conceptual and empirical connections to prior mind-mindedness, to subsequent school readiness, and to each other, which raises the possibility of a developmental process unfolding during the preschool years, which would form a sequential pathway from mind-mindedness to school readiness. This study aimed at testing this pathway.

\section{Mind-mindedness, language, effortful control, and school readiness}

Children who live in a cognitively stimulating family environment, for instance one in which parents are more inclined to comment on children's mental activity, are thought to be advantaged in their language learning (Tamis-LeMonda \& Rodriguez, 2008). According to Laranjo and Bernier (2013), exposure to maternal mind-mindedness could favor the development of child language because the mind-related comments that constitute mind-mindedness necessarily occur within a broader context of discourse. Mind-minded parents are presumed to be more likely to attempt decoding the words that their child tries to pronounce and to try to interpret what he or she tries to communicate (Meins \& Fernyhough, 1999), which is often related to an external object. Given that mind-minded parents, by definition, pay careful attention to their child's line of thinking, they are more likely to reflect a thorough interpretation of their child's mental activity with accompanying context (e.g., 'I see that you want a cup of orange juice'; 'You like this animal, it's called a giraffe'). Such comments are likely to favor children's language development. In support of this, two studies have found that maternal mind-mindedness at 8 months (Meins, Fernyhough, Arnott, Leekam, \& de Rosnay, 2013) or 1 year of age (Laranjo \& Bernier, 2013) predicted larger expressive vocabulary in children at age 2 . For its part, child language is a robust predictor of school readiness (Morgan, Farkas, Hillemeier, Hammer, \& Maczuga, 2015) and has been found to account for associations between family factors and 
school readiness (Forget-Dubois et al., 2009). Accordingly, child language constitutes a potential link through which mind-mindedness could be associated with later school readiness.

One of the ways in which language could operate is by promoting the development of another intermediate skill likely to favor school readiness, namely child effortful control, or the ability to suppress a dominant response in favor of a more context-appropriate response (Rothbart \& Bates, 2006). Children's language skills have been proposed to be their primary tool of self-control (Winsler, Diaz, McCarthy, Atencio, \& Chabay, 1999). Beyond the ability to comprehend verbal directives, language may facilitate reflection and awareness of one's response tendencies, which in turn assist in top-down control (Eisenberg, Sadovsky, \& Spinrad, 2005). Thus, children with more elaborate verbal skills are believed to be better equipped to develop language-based strategies for the inhibition of impulsive responses that is central to effortful control (Vallotton \& Ayoub, 2011). These claims are supported by abundant research documenting significant relations between children's expressive or receptive verbal ability at varying ages and their performance on effortful control tasks (e.g., Carlson, Mandell, \& Williams, 2004; Fuhs \& Day, 2011; Matte-Gagné \& Bernier, 2011).

Finally, effortful control itself is considered important for early learning (Rothbart \& Jones, 1998), because the ability to ignore distractions and suppress impulsive responses in the home and preschool settings may promote children's on-task behavior and sustained engagement with learning activities, and thereby influence their acquisition of pre-academic knowledge (Merz et al., 2014). In line with this, there is evidence that effortful control in the preschool years (Blair \& Razza, 2007; Merz et al., 2014) and kindergarten (Valiente, Lemery-Chalfant, \& Castro, 2010) relates to subsequent pre-academic skills. Given evidence from one study that effortful control also relates to prior mind-mindedness (Bernier, Carlson, Deschênes, \& Matte-Gagné, 
2012), it could constitute an additional stepping stone in the developmental process linking early maternal mind-mindedness and child language to child cognitive school readiness. Hence, mindmindedness could operate indirectly on children's school readiness via a sequential mediated pathway involving both child language and effortful control.

To recap, theory and empirical research suggest the presence of several bivariate links among maternal mind-mindedness, child language, effortful control, and pre-academic knowledge indicative of cognitive school readiness. Furthermore, theory and longitudinal studies tend to suggest that mind-mindedness precedes child language, which precedes effortful control, which itself precedes school readiness. Yet, it is unknown whether maternal mind-mindedness relates to child school readiness, and if so, what the explanatory pathways are.

\section{The current study}

This study set out to examine a sequential mediation model by which early mindmindedness, assessed when children were aged 1 year, would relate to child language (expressive vocabulary) at age 2 , which in turn would relate to effortful control at age 3 and then age 4, which finally would relate to children's cognitive school readiness in kindergarten. Figure 1 presents this conceptual model.

In addition to the longitudinal design that allows for a greater degree of confidence in the sequence of associations than cross-sectional data, we implemented several controls, both to reach conservative predictions and to augment the case for the proposed sequence of causal associations. First, we controlled for child cognitive performance at age 1, concurrent with the mind-mindedness assessment, to rule out the hypothesis that any significant associations could be artefacts of superior initial intellectual skills in the infant triggering more mind-mindedness in the parent as well as better language skills, effortful control, and school readiness in subsequent 
years. Second, family socio-economic status (SES) is a very robust predictor of children's school readiness (see Duncan \& Magnuson, 2005). Given extensive empirical evidence of links between SES and other variables of interest in the current study, in particular child language (Fernald, Marchman, \& Weisleder, 2013), SES could inflate path estimates and is therefore an important confounder that we included in analyses. Finally, studies have often found higher language skills (Fenson et al., 1994), effortful control (Eisenberg et al., 2001), and school readiness (Davies et al., 2015) among girls. Accordingly, child sex was covaried as well.

Another important control, although for different reasons, is maternal sensitivity. Mindmindedness has been conceptualized as a component of sensitive parenting (Meins et al., 2001) and indeed shows empirical links to sensitivity (Bigelow, Power, Bulmer, \& Gerrior, 2015), which itself relates to child school readiness (e.g., NICHD ECCRN, 2003). Controlling for sensitivity assessed concurrently with mind-mindedness thus allowed us to test our predictions specific to mind-mindedness, and ensure that any associations did not represent a halo effect of a more competent mother in the broader sense.

It was expected that maternal mind-mindedness when children were aged 1 year would relate to their cognitive school readiness assessed in kindergarten. We further expected that after adjusting for child initial cognitive ability, family SES, child sex, and maternal sensitivity, the association of mind-mindedness to school readiness would be mediated through language at age 2 and, subsequently, through effortful control at ages 3 and 4 . However, we also examined if any residual direct effect remained that did not operate through the postulated mediated pathway. 


\section{Method}

\section{Participants}

Families were recruited from birth lists of a large Canadian metropolitan area, randomly generated and provided to the research team by the Ministry of Health and Social Services. Criteria for participation were full-term pregnancy and the absence of any known disability or developmental delay in the infant. Five home visits were conducted in total, when children were aged approximately 1 year $(\mathrm{T} 1 ; M=12.61$ months, $S D=0.98), 2$ years $(\mathrm{T} 2 ; M=25.42$ months, $S D=1.13), 3$ years $(\mathrm{T} 3 ; M=36.72$ months, $S D=0.85), 4$ years $(\mathrm{T} 4 ; M=48.83$ months, $S D=$ $0.82)$, and 6 years $(\mathrm{T} 5 ; M=72.34$ months, $S D=2.52)$. The initial sample consisted of 204 children and their mothers. Of those, 185 had T2 data, 183 had T3 data, 175 had T4 data, and finally, 161 had T5 data. Families with complete data did not differ from families lost to attrition on maternal mind-mindedness, sensitivity, child initial cognitive ability, or any demographic characteristic, with one exception: mothers who dropped out were slighted less educated $(M=$ 15.2 years) than those who stayed in the study $(M=15.7), t(202)=1.89, p=.04$. Participants with missing data were included in analyses by estimating the missing values as described below.

Mothers were between 20 and 45 years old $(M=31.5)$ at the beginning of the study, and had between 8 and 18 years of formal schooling $(M=15.6)$. Fathers were aged between 21 and 52 years $(M=34.0)$ and had between 6 and 21 years of schooling $(M=15.4)$. Most parents $(83.8 \%)$ were of European descent. Other ethnic origins included Caribbean (4.4\%), LatinAmerican (3.9\%), Middle-Eastern or North African (4.4\%), and mixed or non-specified (3.4\%). Most families (92\%) spoke French at home; 8\% spoke English. Family income varied from less than $\$ 20,000 \mathrm{CDN}$ to more than $\$ 100,000 \mathrm{CDN}$, with an average in the $\$ 60,000$ to $\$ 79,000 \mathrm{CDN}$ 
bracket. Approximately $96 \%$ of parental couples were intact at the T1 assessment, and $84 \%$ still were at $\mathrm{T} 5$.

\section{Measures: Key model variables}

Maternal mind-mindedness. A 10-minute videotaped mother-infant free play from the T1 visit was rated using Meins and Fernyhough's (2010) coding system. Five categories of mindrelated comments were assessed: (a) desires and preferences; (b) cognitions; (c) emotions; (d) epistemic states; and (e) talking on the infant's behalf. Each mind-related comment was noted, and then classified as appropriate or non-attuned. Following Meins and Fernyhough's (2010) guidelines, a comment is considered appropriate when it fits at least one of three criteria: the coder agrees with the mother's comment on her infant's state of mind, the comment clarifies how to proceed after a lull in the interaction, or the comment is linked in a meaningful way with a past, future or current activity (e.g., "Do you want to take the train to visit grandma tomorrow?" would be appropriate if said while the child is playing with a toy train. In contrast, the same statement made while the infant is visibly interested in something else than a train or grandma would be rated as non-attuned). The resulting score was the total number of appropriate mindrelated comments made during the interaction. A randomly selected subset of $20 \%$ of videotapes was coded by a second rater, blind to all other measures. Inter-rater reliability (intra-class correlation; ICC) was .92. Because non-attuned mind-related comments were extremely rare in this low-risk sample (almost $94 \%$ of mothers made no such comments at all), this type of comments was not examined.

Child language ability. At T2, mothers completed the short-form version of the MacArthur Communicative Development Inventory (MCDI; Fenson et al., 1993), a parental report on children's expressive vocabulary. Parents are asked to identify from a list which words 
they have heard their child say. Fenson et al. (1994) report excellent reliability indices for the instrument. The original 688-item MCDI was validated in French for a Canadian population by Frank, Trudeau, and Poulin-Dubois (1996). Based on these two longer versions, Dionne, Tremblay, Boivin, Laplante and Pérusse (2003) developed brief 102-item versions for both French- and English-speaking Canadian populations. The authors report excellent and equivalent properties for both versions. In the current study, Dionne et al.'s (2003) brief French or English version was used, according to the language spoken in the family.

Effortful control at age 3. We used a simple Delay of Gratification task (Kochanska et al., 2000) at T3 to assess children's capacity to inhibit a dominant response. Children first had to choose their preferred reward (raisins, Goldfish Crackers or Froot Loops). The experimenter then explained to the children that they could eat the treat, placed under a transparent cup in front of them, only when she rang the bell. Four trials of increasingly longer duration were used $(5,15$, 30 and 45 seconds). Scores consisted of the number of seconds the child waited on each trial before touching the treat (regardless of whether s/he ate it or not). The total wait score (maximum: 95 seconds) was used in analyses. Because all children who completed the task successfully completed the four trials, the meaning of this total score was equivalent for all children. Children's performance on this task shows convergent validity with other behavioral measures of effortful control at age 3 (Kochanska, Aksan, Penney, \& Doobay, 2007).

Effortful control at age 4. We used a battery of tasks to assess effortful control at T4. These tasks represent different levels of difficulty for 4 year-old children (Carlson, 2005), thus capturing a range of individual differences.

Whisper (Kochanska, Murray, Jacques, Koenig, \& Vandegeest, 1996). As a practice trial, the experimenter asked children if they could whisper their own name and hers (all children were 
able to do this). The experimenter then presented a series of 10 cards with illustrations of cartoon characters (6 familiar, 4 unfamiliar to most preschoolers). Children were told to whisper the names of each character and that it was okay if they did not know all of them. Unfamiliar characters were included so that children would be more excited upon seeing a familiar one (and therefore more likely to shout out the name). On each trial they received a score of 0 if they blurted out the name or used a normal voice and a score of 1 if they whispered. Most children $(n$ $=158)$ knew all six "familiar" characters; the remaining children knew five $(n=16)$ or four $(n=$ 1). No child knew any of the four characters intended to be unfamiliar. All trials in which children did not know the character's name were unscored. The final score was the proportion of names of recognized characters that the child was able to whisper.

Tower (Kochanska et al., 1996). Children were invited to help the experimenter build a tower with blocks. The experimenter said they would take turns and demonstrated turn-taking to ensure that the child understood what it meant. After this brief practice, the experimenter reminded the child that they would build a tower together "while taking turns". She placed the first block and told the child it was his or her turn to go next. Thereafter, for the nine remaining blocks, the experimenter did not remind the child of the turn-taking rule. Instead, she waited for an explicit signal from the child to take a turn. The score consisted of the proportion of blocks placed by the experimenter, with a maximum of 50\% (50\% indicating that the child was able to let the experimenter place a block each time he or she placed one). This procedure was repeated once, and the average score across the two tasks was retained.

Count and Label (Gordon \& Olson, 1998). Children were shown three objects (a key, a small shoe, and a toy horse) and asked to label them. Then the experimenter suggested they count the objects. She demonstrated how to count and label the objects (e.g., "one is a key, two is 
a shoe, three is a horse"), and asked the child to do likewise. A second similar trial was then administered, using a spoon, a book, and a toy duck. Children's performance on each trial was scored as impulsive and thus incorrect if (a) they labeled the objects and then counted them or vice-versa, or (b) if they said "one is a key, one is a shoe, one is a horse" or the equivalent. Total scores could thus vary from 0 to 2 .

Less is More (Carlson, Davis, \& Leach, 2005). Children were asked to select between a larger and smaller array of candy placed in shallow trays (five vs. two jelly beans; all children initially indicated that they liked jelly beans and preferred the larger amount). Children were then told that whichever tray they chose, those treats would go to "the mean sheep", a toy sheep which had been placed on the table near the experimenter, and that they would get to keep the treats in the other, non-selected tray. Children therefore needed to refrain from choosing the tray with the larger amount, and rather point to the smaller amount in order to get the most candies. The candies accumulated in clear plastic cups (one for the child and one for the sheep) across trials. After a brief practice and verbal rule check, eight test trials followed, with a rule reminder halfway through, but without explicit feedback. The final score consisted of the number of correct (smaller) treat selections.

Simon Says (Strommen, 1973). In this version of a popular game, the experimenter and child stood facing each other. The experimenter explained that the child should follow a command only if she prefaced the command with "Simon says." The child was to remain perfectly still otherwise. The experimenter issued commands in quick succession and performed all actions, regardless of whether it was a "Simon says" trial. There were 10 trials (5 with and 5 without "Simon says"). Performance on the "non-Simon says" trials was taken as final score. 
To give equal weights to these five tasks despite their different scales, and in line with prior studies with toddlers and preschoolers that combined these or similar tasks into an effortful control composite (Kochanska et al., 2000; Merz et al., 2014), a standardized average of child performance on the five tasks ( $r$ s between .17 and .34 ) was computed and retained as the effortful control index with acceptable internal consistency $(\alpha=.62){ }^{1}$

School readiness. At T5, we used the Lollipop test (Chew \& Morris, 1984) to assess children's school readiness. The Lollipop is a well-validated tool that assesses the knowledge and cognitive skills underlying school readiness. It is individually administered and composed of four subscales: knowledge of colors and shapes, of spatial notions (beside, under, etc.), of numbers, and of letters. These scales are then summed into a total school readiness score (maximum $=71$ ). In the current study, all children who completed the Lollipop completed all four scales; accordingly, use of the total score was appropriate. This score correlates highly $(r=$ .76) with that on the Metropolitan Readiness Tests (Chew \& Morris, 1984), and has been shown to predict school achievement (Eno \& Woehlke, 1995) up to 4th grade (Chew \& Morris, 1989). The French version of the Lollipop for Canadian populations is also well-validated (ForgetDubois et al., 2009; Venet, Normandeau, Letarte, \& Bigras, 2003) and holds unique predictive power for 1 st grade academic achievement above and beyond general cognitive ability (Lemelin et al., 2007). We used the French or English version according to the language spoken in the family.

\section{Measures: Covariates}

In addition to child sex, the following three covariates were measured.

Maternal sensitivity. Maternal sensitivity was assessed at T1 (1 year) using the Maternal Behavior Q-Sort (MBQS; Pederson \& Moran, 1995). A trained research assistant noted maternal 
behaviors throughout a home visit (described below) and rated the MBQS immediately upon returning to the laboratory, based on observations conducted throughout the visit. The 90 items describing potential maternal behaviors were sorted into nine piles, ranging from "very unlike" to "very similar" to the observed mother's behaviors. The observer's sort was then correlated with a criterion sort representing the prototypically sensitive mother, which is provided by the developers of the instrument. This correlation constitutes the sensitivity score. The MBQS is significantly correlated with other measures of maternal behavior (Pederson \& Moran, 1995), and shows good temporal stability (Behrens, Parker, \& Kulkofsky, 2014) and predictive validity (Van IJzendoorn, Vereijken, Bakermans-Kranenburg, \& Riksen-Walraven, 2004). In the current study, approximately $20 \%$ of home visits were randomly chosen to be conducted by two research assistants, who completed the MBQS independently. Agreement between the two raters' sorts was very good, $\mathrm{ICC}=.86$.

Child cognitive ability. Also at T1, we used the Mental Development Index (MDI) of the Bayley Scales of Infant Development (2nd edition; Bayley, 1993) to assess child cognitive performance concurrent to the mind-mindedness assessment. The MDI is a well-standardized test of cognitive development for children aged 1 to 42 months.

Family socio-economic status (SES). Family SES is a standardized average of maternal education, paternal education, and family income ( $r$ s between .51 and .59$)$.

\section{Procedure}

Children and their mothers were visited in their homes five times. At T1 (1 year), the home visit was modeled after the work of Pederson and Moran (1995), and aimed at challenging the mother's capacity to divide her attention between competing demands, thus reproducing the natural conditions of daily life when caring for an infant. Visits included a brief interview with 
the mother, research tasks with the infant (including the MDI described above), a 10-minute free play, and questionnaires that the mother was asked to complete while the infant was not occupied by the research assistant. Observations conducted throughout these home visits were used to assess maternal sensitivity with the MBQS, as described above. In the 10-minute mother-infant play sequence, mothers were asked to play as they normally did with their infant, using a standard set of toys brought by the research assistant. This interaction was videotaped and later coded for maternal mind-mindedness as described above.

At T2 (2 years), mothers reported on their children's expressive vocabulary by responding to the MCDI in an interview format with a research assistant. At T3 and T4 (3 and 4 years), research assistants administered the effortful control tasks described above to children. Finally, the Lollipop test was administered in families' homes when children were in the Spring of their kindergarten year (February through April; T5). Whereas T1 to T4 visits were scheduled around the child's birthday to maintain a narrow age window for infancy, toddlerhood and preschool visits, the kindergarten visit was rather aligned with the school calendar, to ensure roughly equivalent exposure to kindergarten experiences at the time of the school readiness assessment. This explains the higher standard deviation for child age at this visit, presented in the Participants section above. Nonetheless, we also examined whether duration of schooling (i.e., number of weeks since the beginning of the academic year) influenced readiness scores. School readiness was unrelated to duration of schooling, $r=.11, p=.22$, which consequently was not covaried in the analyses.

Average time lag between time points was 12.8 months between $\mathrm{T} 1$ and $\mathrm{T} 2(S D=1.34)$, 11.4 months between $\mathrm{T} 2$ and $\mathrm{T} 3(S D=1.22), 12.1$ months between $\mathrm{T} 3$ and $\mathrm{T} 4(S D=1.06)$, and finally 23.5 months between $\mathrm{T} 4$ and $\mathrm{T} 5(S D=2.68)$. 


\section{Analytic plan}

After initial screening of the data, zero-order correlations were computed to examine bivariate associations between variables. Although not necessary to demonstrate mediation (Hayes, 2013), the presence of significant associations between predictors, mediators, and outcomes is advantageous, as it provides a more compelling basis from which to test for mediation (Kline, 2011; MacKinnon, Lockwood, Hoffman, West, \& Sheets, 2002).

Next, the hypothesized serial mediation model displayed in Figure 1 was tested by computing direct and indirect effects with a series of ordinary least squares (OLS) regressions and the bootstrapping procedure recommended by Preacher and Hayes (2008). Bias-corrected bootstrapping generates an empirical approximation of the sampling distribution of a statistic and uses this distribution to construct bias-corrected confidence intervals (CI). In the case of mediation, the bootstrapping procedure yields bias-corrected CIs for all indirect effects (Hayes, 2013). Whenever zero is not contained within the bootstrapped CI, one can conclude that the indirect (i.e., mediated) effect is significant. We used the PROCESS macro in SPSS $22(10,000$ bootstraps and 95\% CI; Hayes, 2013) to run these analyses. Importantly for our purposes, PROCESS allows for sequential mediation analysis. This method, also referred to as a "serial multiple mediator model", allows estimation of multiple mediators that are serially linked in a causal chain, such that the first mediator affects the second, the second affects the third, and so on (Hayes, 2013). We used this method to test the hypothesized mediation model, in which maternal mind-mindedness predicts child language ability, which in turn predicts 3-year effortful control, which predicts 4-year effortful control, which, finally, predicts school readiness (Figure 1). We controlled for family SES, maternal sensitivity, as well as child sex and cognitive performance (at 1 year, concurrent to the mind-mindedness assessment) by modeling them to all 
mediators and to the outcome. Given that PROCESS does not provide standardized coefficients, all scores were standardized before being entered in the model, so that the unstandardized estimates of direct and indirect paths (and related CIs) would be interpretable as standardized.

The mediation model was also submitted to structural equation modeling (SEM) using the maximum likelihood (ML) method of estimation in EQS (Version 6.1; 2012). Although not necessary to demonstrate mediation (Hayes, 2013), SEM was used here because it provides informative fit indices for the overall model, and also allows cross-checking of the results since it is based on the ML rather than OLS method of estimation.

Given that PROCESS and EQS use listwise deletion, which is no longer recommended (Jelicic, Phelps, \& Lener, 2009), missing data were first estimated with multiple imputation in SPSS 22 (10 imputations, subsequently averaged for analysis; Schafer, 1997), and the resulting complete data set was then submitted to PROCESS and EQS. Mediation analyses were thus run on the total sample of $\mathrm{N}=204$. Finally, note that although we use terminology that implies causation (e.g., direct and indirect effects) in order to respect statistical conventions (Hayes, 2013), this non-experimental design does not allow for conceptual causal inference.

\section{Results}

\section{Preliminary analyses}

Table 1 presents the descriptive statistics for the key study variables. All distributions were within the bounds of moderate normality (skewness $<3.0$; kurtosis $<7.0$; Curran, West, \& Finch, 1996; Kline, 2011), except for 3-year effortful control. However, transforming these scores to normality did not improve the results; accordingly, we used original untransformed scores in all subsequent analyses. Data were next screened for extreme scores. No multivariate outliers were found, but five univariate outliers were found on 3-year effortful control, two on 4- 
year effortful control, and one on school readiness. In all cases, these children's scores fell at the lower-end of the scale; therefore, these scores were substituted with the highest observed value that fell within -3.29 standardized scores (as recommended by Tabachnick \& Fidell, 2013).

Table 2 presents the zero-order correlations among the study variables. A first observation is that the predictor, mediators and outcome were all inter-related (lines $1-5$ and columns $2-5$ ), with the exception of effortful control at age 3 with school readiness. Second, column 7 indicates that controlling for family SES is especially important, given that it relates positively to all key study variables, and therefore could substantially inflate path estimates if not covaried. Lastly, the other three covariates (columns 6,8 , and 9) each relate to at least two of the key variables, suggesting that they also could inflate path estimates if not modeled. Overall, the initial pattern of bivariate links provided a sound basis on which to test the postulated mediation model.

\section{Main analyses}

As displayed in Figure 2, the serial multiple mediator model indicated that above and beyond the effects of child initial cognitive performance, family SES, child sex, and maternal sensitivity, maternal mind-mindedness predicted child language ability $(\mathrm{a}=.14, p=.046)$, which in turn predicted 3-year effortful control $(b=.16, p=.031)$, which predicted 4-year effortful control $(\mathrm{c}=.22, p=.001)$, which, finally, predicted school readiness $(\mathrm{d}=.19, p=.016)$. These coefficients represent unique links, over and above all other paths. The overall indirect effect linking maternal mind-mindedness to child school readiness via language, 3-year effortful control, and 4-year effortful control in serial, after adjusting for the four covariates, was small but significant $(\mathrm{abcd}=.0009$, bias-corrected bootstrapped $\mathrm{CI}=.0001-.0047)$. 
The mediation analysis in PROCESS yielded other pertinent information. First, the residual direct effect of maternal mind-mindedness on child school readiness, after accounting for the indirect effects, was negligible $(\mathrm{e}=.05, p=.489)$. According to Kline (2011), statistically significant indirect effects in the absence of significant residual direct effects represent the strongest demonstration for mediation. Thus, the overall effect of maternal mind-mindedness on child school readiness could entirely be accounted for by the causal chain involving language, 3year effortful control, and 4-year effortful control in series.

Second, all other possible indirect effect models, which are automatically tested by PROCESS, were non-significant (i.e., their CIs included 0). This indicates that dropping any mediator or pair of mediators from the model reduces its fit and yields a non-significant model. Therefore, the mediation is truly sequential: all three postulated mediators are necessary to account for the effect of maternal mind-mindedness on child school readiness; none of the mediators can be bypassed in describing the underlying developmental process.

Finally, PROCESS also tests all possible direct effects. This allowed for the observation that no path other than those displayed in Figure 2 was significant. Thus, when accounting for all other paths in the model, no predictor was significantly directly linked to any outcome other than that immediately following it temporally. For instance, mind-mindedness did not relate to 3-year effortful control, 4-year effortful control or school readiness other than through its indirect effect on 3-year effortful control transiting via language, and so on for all possible direct paths. This suggests that the fully mediated model is the best representation of the data (MacKinnon, 2008).

Based on these latter results, the first model that we fitted in SEM was a fully mediated model, involving only the paths displayed in Figure 2. Therefore, the pattern of parameters was restricted so that each variable was estimated only in relation to the variables that immediately 
preceded or followed it in the theoretical model (and relevant covariates as appropriate). The other paths were fixed at 0 . This model showed excellent fit to the data, $\chi^{2}(3)=3.43, p=.33$, $\chi^{2} / \mathrm{df}=1.14 ;$ comparative fit index $=.99 ;$ non-normed fit index $=.97 ;$ standardized root mean square residual $=.035$; and root mean square error of approximation $=.025$. All specified paths were significant $(p<.05)$, and very similar in magnitude to those presented above, yielded by PROCESS. Post-hoc analyses were conducted next to explore the relevance of more complex models. Using the Lagrange Multiplier (LM) Test, we tested the effect of adding parameters to the model. Congruent with the results obtained with PROCESS, the LM test revealed that no additional path would be significant (univariate analysis) or would significantly improve the fit of the model (multivariate analysis), which confirmed that the fully mediated model adequately represented the observed data.

\section{Discussion}

Following recommendations to investigate the mechanisms through which the family environment relates to children's school readiness (Forget-Dubois et al., 2009; NICHD ECCRN, 2003), this study tested a serial mediation model consistent with a developmental process by which maternal mind-mindedness in infancy would favor children's cognitive school readiness through its intermediate impact on child language at age 2, which in turn would support effortful control at ages 3 and then 4, which finally would promote school readiness in kindergarten. Both SEM and OLS path analyses corroborated this model, suggesting that the prospective association between mind-mindedness and cognitive school readiness was entirely accounted for by the proposed sequence of mediators. The analyses also indicated that no other direct or indirect effects were significant, suggesting the truly sequential nature of the mediated pathway, and that no mediator could be bypassed in describing the underlying developmental process. Hence, 
although causality cannot be determined based on this non-experimental design, the results are consistent with the notion that early mind-mindedness promotes children's cognitive school readiness, and does so through intermediate effects on child language and subsequent effortful control in the toddler and preschool years.

These results were robust, in that they held after adjusting for a set of covariates (child initial cognitive ability, family SES, child sex, and maternal sensitivity) that are linked to several of the key model components, as observed both in previous research and in the current sample (Table 2). Furthermore, the longitudinal design allowed for using the correct temporal ordering of predictor, mediators, and outcome. Although not cross-lagged, the longitudinal design also allowed us to tend toward Cole and Maxwell's (2003) recommendations to predict later outcomes independent of earlier outcomes, in this case by adjusting for child initial cognitive ability. Controlling for child cognitive ability concurrent to the mind-mindedness assessment allowed us to rule out the third-variable hypothesis of child general intellectual ability underpinning child language capacities as well as later cognitive school readiness, while also triggering more mind-mindedness in mothers. We also controlled for maternal sensitivity assessed at the same time as mind-mindedness, strengthening the case for a specific role of mindmindedness rather than general parenting quality. Finally, there was minimal shared method variance in the design, with the assessment of child language being based on maternal reports, and all other constructs assessed with entirely different behavioral tasks administered at least 1year apart. Overall, the estimates yielded by the model can be considered conservative, and it appears very unlikely that the mediated process uncovered reflects methodological artefacts.

Nonetheless, all effects (direct and indirect) were small in magnitude. On the one hand, this is not unexpected in the context of a longitudinal study with predictive measures taken 
several years prior to the outcome and adjustment for several critical confounders, and is consistent with previous research on mechanisms accounting for links between family factors and school readiness, which found significant but small indirect effects (Forget-Dubois et al., 2009; NICHD ECCRN, 2003). When interpreting the coefficients from the model, it is helpful to remember that they represent partial coefficients adjusted for all other paths, including those involving covariates. Also, because the indirect effect is the product of three mediated paths, it is mathematically expected that the resulting coefficients be quite small. Nevertheless, the associations observed here, while arguably robust for the reasons invoked above, were small in magnitude. Accordingly, these results should be seen as adding one piece to the complex developmental puzzle linking parenting behaviors to school readiness, which probably also includes children's attentional capacities (Razza, Martin, \& Brooks-Gunn, 2010) and parentchild attachment, which has often been found to relate to parental mind-mindedness (e.g., Laranjo, Bernier, \& Meins, 2008) and children's effortful control (e.g., Nordling, Boldt, O'Bleness, \& Kochanska, 2016).

Other factors may also intervene between parental mind-mindedness and child school readiness. For instance, parent-child joint book reading is a well-documented predictor of children's pre-academic skills (Bus, Van IJzendoorn, \& Pellegrini, 1995). It is conceivable that mind-minded parents could be more likely to read books to their children, which would constitute another pathway linking mind-mindedness to school readiness. Also, high-quality child care during early childhood predicts higher cognitive school readiness (Côté et al., 2013), and there is some evidence that families with fewer risk factors (that is, those with higher education and stimulating home environments) may be more likely to use daycare (Geoffroy et al., 2012). Consequently, another possible hypothesis is that parents presenting higher mind- 
mindedness may be more likely to use daycare, thus further fostering their young children's school readiness. Unfortunately, this hypothesis could not be tested in the current study because nearly all children attended daycare (due to provincial policies ensuring equal access to daycare regardless of family income). All in all, although the sequence of mediators proposed here did suffice to empirically explain the associations between mind-mindedness and school readiness observed in the current sample, there is no reason to exclude other explanatory pathways. In fact, it is likely that other factors such as the use of quality daycare and shared book reading also play a role in these associations. Alternatively, factors such as daycare and shared book reading could operate outside of the path that begins with mind-mindedness, and have direct effects on school readiness, independent of those of mind-mindedness.

Aside from other potential mediators, an important predictive factor to consider in future research is paternal mind-mindedness. Although fathers have received little attention thus far in the mind-mindedness literature (and, to a large extent, in the school readiness literature), research in neighboring domains shows without a doubt that the quality of paternal behavior is important for child cognitive development (e.g., Meuwissen \& Carlson, 2015). It is likely that fathers' mind-mindedness relates to their children's school readiness, and such links could conceivably operate through the same or similar mediators as those considered here.

Considering its origins in Vygotskian theories and studies of cognitive development (Meins, 1997), it is surprising that mind-mindedness has almost exclusively been examined in relation to child socio-emotional functioning, except for two studies that found it to relate to child language (Laranjo \& Bernier, 2013; Meins et al., 2013). Given solid theoretical grounds to expect parental mind-mindedness to promote child cognitive development, and the current results suggesting that mind-mindedness is related to the cognitive aspect of school readiness 
five years later, we suggest that the potential of mind-mindedness to bolster children's cognitive development may have been under-estimated, and deserves renewed scrutiny.

While the longitudinal design, strict controls implemented, and lack of shared method variance provide some confidence in the directionality of the developmental process suggested by the mediation model examined here, it is worth reiterating that the terms "direct and indirect effects" were used in the spirit of respecting recommendations pertaining to the statistical tool chosen (Hayes, 2013), and should not be understood to mean that the observed path estimates are indicative of causal relations. The non-experimental nature of the design is the greatest limitation of this study. One way to overcome this limitation partially would be to use a panel design, with all variables assessed at each time point, which allows for disentangling the directionality of associations and identifying bidirectional links. This may be especially important with the developmental process examined here: as summarized by Eisenberg et al. (2005), there is evidence of reciprocal influences between children's language skills, their regulatory abilities (e.g., effortful control), and their academic performance, and more regulated children may also elicit richer language input from their parents. Although the use of a panel design was challenging in the current case, owing to the difficulty assessing constructs such as school readiness and effortful control before age 3, such a design would have gone a long way toward the identification of bidirectional links, and should be considered in future research.

A potentially important confound that was not assessed is the richness of maternal general verbal input when interacting with the infant, which is a robust predictor of children's cognitive development (Hoff \& Naigles, 2002). One may presume that mothers who talk a lot to their infants tend to use mind-related language more frequently than less verbose mothers. While some researchers use proportional rather than frequency scores to control for verbosity when 
scoring mind-mindedness (Meins \& Fernyhough, 2010), we used frequency scores, meaning that we cannot exclude the possibility that mothers who scored high for mind-mindedness were also mothers who provided a rich language environment more broadly. Given, however, that maternal verbal input during mother-infant interactions is robustly related to maternal education (Hoff, 2003; Rowe, 2008), which was controlled here, it is unlikely that what appear to be effects of mind-mindedness were merely a reflection of a rich maternal discourse while interacting with the infant. In fact, studies that use both frequency and proportional scores of mind-mindedness find identical patterns of results with both scores, suggesting that the importance of mind-mindedness is not due to the richness of maternal verbal input (Meins et al., 2003; Meins et al., 2013). Nonetheless, we cannot rule out that hypothesis entirely. Likewise, we cannot exclude a potential role of maternal verbal IQ (potentially genetically transmitted to the child) in the mediation process found here; however, given strong relations between maternal verbal IQ and education (Meador et al., 2011; Rowe, 2008), it appears improbable that maternal IQ would explain a large proportion of the associations found here after controlling for maternal education.

Another methodological limitation is that due to time constraints during a home visit entailing several assessments, 3-year effortful control was assessed with only one delay of gratification task (vs. a battery of five tasks at 4 years), and was in fact the only non-normally distributed variable, and the only one that did not show a statistically significant bivariate link to school readiness. Nonetheless, 3-year effortful control did relate to all other model components, remained associated with its immediate antecedent and outcome in the final model, and could not be bypassed in the mediated pathway. Still, a more thorough assessment may have yielded stronger results for both direct and indirect links. 
On a conceptual level, we chose to focus on the cognitive aspect of school readiness, in light of meta-analytic data showing that pre-academic knowledge is a vastly superior predictor of academic achievement than child social or behavioral functioning at school entry (Duncan et al., 2007). Still, it is widely accepted that school readiness is more than a strictly academic concept and also includes emotional, social, and behavioral domains (Blair \& Raver, 2015; Davies et al., 2015). These other aspects of school readiness deserve attention as well. Also, it has been suggested that parental recognition of infant mental states is not always verbal as with mindmindedness, but can also be implicit and manifested non-verbally, for instance through parental embodied mentalizing (PEM; Shai \& Belsky, 2011). However, a measure of PEM was not available here.

This study suggested that a developmental process unfolded during the preschool years that began with higher maternal mind-mindedness during mother-infant interactions, continued with more developed language skills in toddlers and then greater effortful control in preschoolers, and culminated in better cognitive school readiness in kindergarteners. Given the demonstrated importance of academic achievement for many aspects of children's lives (Henry, Knight, \& Thornberry, 2011), and some suggestion that it may be possible to increase parental mind-mindedness through intervention (Gurney-Smith, Granger, Randle, \& Fletcher, 2010), the promotion of mind-mindedness among parents may be one way to set in motion a developmental cascade with long-term positive consequences on children's academic achievement and healthy development. 


\section{References}

Bayley, N. (1993). Bayley Scales of Infant Development (2nd ed.). San Antonio, TX: Psychological Corporation.

Behrens, K. Y., Parker, A. C., \& Kulkofsky, S. (2014). Stability of maternal sensitivity across time and contexts with Q-sort measures. Infant and Child Development, 23, 532-541. doi:10.1002/icd.1835

Bernier, A., Carlson, S. M., Deschênes, M., \& Matte-Gagné, C. (2012). Social factors in the development of early executive functioning: A closer look at the caregiving environment. Developmental Science, 15, 12-24. doi:10.1111/j.1467-7687.2011.01093.x

Bigelow, A. E., Power, M., Bulmer, M., \& Gerrior, K. (2015). The relation between mothers' mirroring of infants' behavior and maternal mind-mindedness. Infancy, 20, 263-282. doi:10.1111/infa.12079

Blair, C., \& Raver, C. C. (2015). School readiness and self-regulation: A developmental psychobiological approach. Annual Review of Psychology, 66, 711-731. doi:10.1146/annurev -psych-010814-015221

Blair, C., \& Razza, R. P. (2007). Relating effortful control, executive function, and false belief understanding to emerging math and literacy ability in kindergarten. Child Development, 78, 647-663. doi:10.1111/j.1467-8624.2007.01019.x

Bus, A. G., Van IJzendoorn, M. H., \& Pellegrini, A. D. (1995). Joint book reading makes for success in learning to read: A meta-analysis on intergenerational transmission of literacy. Review of Educational Research, 65, 1-21. doi:10.3102/00346543065001001

Carlson, S. M. (2005). Developmentally sensitive measures of executive function in preschool children. Developmental Neuropsychology, 28, 595-616. doi:10.1207/s15326942dn2802_3 
Carlson, S. M., Davis, A. C., \& Leach, J. G. (2005). Less is more executive function and symbolic representation in preschool children. Psychological Science, 16, 609-616. doi:10.1111/j.1467-9280.2005.01583.x

Carlson, S. M., Mandell, D. J., \& Williams, L. (2004). Executive function and theory of mind: Stability and prediction from ages 2 to 3. Developmental Psychology, 40, 1105-1122. doi:10.1037/0012-1649.40.6.1105

Carlton, M. P., \& Winsler, A. (1999). School readiness: The need for a paradigm shift. School Psychology Review, 28, 338. Retrieved from http://search.proquest.com/openview/ d1f90d65152a4533507ee0ba0b952277/1?pq-origsite=gscholar

Chew, A. L., \& Morris, J. D. (1984). Validation of the Lollipop test: A diagnostic screening test of school readiness. Educational and Psychological Measurement, 44, 987-991. doi:10.1177 $/ 0013164484444022$

Chew, A. L., \& Morris, J. D. (1989). Predicting later academic achievement from kindergarten scores on the Metropolitan Readiness Tests and the Lollipop Test. Educational and Psychological Measurement, 49, 461-465. doi:10.1177/0013164489492019

Cole, D. A., \& Maxwell, S. E. (2003). Testing mediational models with longitudinal data: Questions and tips in the use of structural equation modeling. Journal of Abnormal Psychology, 112, 558-577. doi:10.1037/0021-843X.112.4.558

Connell, C. M., \& Prinz, R. J. (2002). The impact of childcare and parent-child interactions on school readiness and social skills development for low-income African American children. Journal of School Psychology, 40, 177-193. doi:10.1016/S0022-4405(02)00090-0 
Côté, S. M., Mongeau, C., Japel, C., Xu, Q., Séguin, J. R., \& Tremblay, R. E. (2013). Child care quality and cognitive development: Trajectories leading to better pre-academic skills. Child Development, 84, 752-766. doi:10.1111/cdev.12007

Curran, P. J., West, S. G., \& Finch, J. F. (1996). The robustness of test statistics to nonnormality and specification error in confirmatory factor analysis. Psychological Methods, 1, 16-29. doi:10.1037/1082-989X.1.1.16

Davies, S., Janus, M., Duku, E., \& Gaskin, A. (2015). Using the early development instrument to examine cognitive and non-cognitive school readiness and elementary student achievement. Early Childhood Research Quarterly, 35, 63-75. doi:10.1016/j.ecresq.2015.10.002

Dionne, G., Tremblay, R., Boivin, M., Laplante, D., \& Pérusse, D. (2003). Physical aggression and expressive vocabulary in 19-month-old twins. Developmental Psychology, 39, 261-273. doi:10.1037/0012-1649.39.2.261

Duncan, G. J., Dowsett, C. J., Claessens, A., Magnuson, K., Huston, A. C., Klebanov, P., ... Japel, C. (2007). School readiness and later achievement. Developmental Psychology, 43, 1428-1446. doi:10.1037/0012-1649.43.6.1428

Duncan, G. J., \& Magnuson, K. A. (2005). Can family socioeconomic resources account for racial and ethnic test score gaps? The Future of Children, 15, 35-54. doi:10.1353 /foc. 2005.0004

Eisenberg, N., Gershoff, E. T., Fabes, R. A., Shepard, S. A., Cumberland, A. J., Losoya, S. H., ... Murphy B. C. (2001). Mother's emotional expressivity and children's behavior problems and social competence: Mediation through children's regulation. Developmental Psychology, 37, 475-490. doi:10.1037/0012-1649.37.4.475 
Eisenberg, N., Sadovsky, A., \& Spinrad, T. L. (2005). Associations of emotion-related regulation with language skills, emotion knowledge, and academic outcomes. New Directions for Child and Adolescent Development, 109, 109-118. doi:10.1002/cd.143

Eisenberg, N., \& Spinrad, T. L. (2004). Emotion-related regulation: Sharpening the definition. Child Development, 75, 334-339. doi:10.1111/j.1467-8624.2004.00674.x

Eno, L., \& Woehlke, P. (1995). Use of the Lollipop Test as a predictor of California Achievement Test scores in kindergarten and transitional first-grade status. Psychological Reports, 76, 145-146. doi:10.2466/pr0.1995.76.1.145

Fenson, L., Dale, P. S., Reznick, J. S., Bates, E., Thal, D. J., Pethick, S. J., ... \& Stiles, J. (1994). Variability in early communicative development. Monographs of the Society for Research in Child Development, 59, 1-185. doi:10.2307/1166093

Fenson, L., Dale, P. S., Reznick, J. S., Thal, D., Bates, E., Hartung, J. P., ... Reilly, J. S. (1993). The MacArthur Communicative Development Inventories: User's Guide and Technical Manual. San Diego, CA: Singular Publishing Group.

Fernald, A., Marchman, V. A., \& Weisleder, A. (2013). SES differences in language processing skill and vocabulary are evident at 18 months. Developmental Science, 16, 234-248. doi:10.1111/desc.12019

Forget-Dubois, N., Dionne, G., Lemelin, J. P., Pérusse, D., Tremblay, R. E., \& Boivin, M. (2009). Early child language mediates the relation between home environment and school readiness. Child Development, 80, 736-749. doi:10.1111/j.1467-8624.2009.01294.x

Frank, I., Trudeau, N., \& Poulin-Dubois, D. (1996). Inventaire MacArthur de la communication: Mots et énoncés. Unpublished manuscript, Concordia University, Montreal, Canada. 
Fuhs, M. W., \& Day, J. D. (2011). Verbal ability and executive functioning development in preschoolers at Head Start. Developmental Psychology, 47, 404-416. doi:10.1037/a0021065

Ganger, J., \& Brent, M. R. (2004). Re-examining the vocabulary spurt. Developmental Psychology, 40, 621-632. doi:10.1037/0012-1649.40.4.621

Geoffroy, M., Séguin, J., Lacourse, É., Boivin, M., Tremblay, R., \& Côté, S. (2012). Parental characteristics associated with childcare use during the first 4 years of life: Results from a representative cohort of Québec families. Canadian Journal of Public Health, 103, 76-80. doi:10.17269/cjph.103.2764

Gordon, A. C., \& Olson, D. R. (1998). The relation between acquisition of a theory of mind and the capacity to hold in mind. Journal of Experimental Child Psychology, 68, 70-83. doi:10.1006/jecp.1997.2423

Gurney-Smith, B., Granger, C., Randle, A., \& Fletcher, J. (2010). 'In time and in tune'-the fostering attachments group: Capturing sustained change in both caregiver and child. Adoption \& Fostering, 34, 50-60. doi:10.1177/030857591003400406

Hayes, A. F. (2013). An introduction to mediation, moderation, and conditional process analysis. New York, NY: The Guilford Press.

Henry, K. L., Knight, K. E., \& Thornberry, T. P. (2011). School disengagement as a predictor of dropout, delinquency, and problem substance use during adolescence and early adulthood. Journal of Youth and Adolescence, 41, 156-166. doi:10.1007/s10964-011-9665-3

Hoff, E. (2003). The specificity of environmental influence: Socioeconomic status affects early vocabulary development via maternal speech. Child Development, 74, 1368-1378. doi:10.1111/1467-8624.00612 
Hoff, E., \& Naigles, L. (2002). How children use input to acquire a lexicon. Child Development, 73, 418-433. doi:10.1111/1467-8624.00415

Hubbs-Tait, L., Culp, A. M., Culp, R. E., \& Miller, C. E. (2002). Relation of maternal cognitive stimulation, emotional support, and intrusive behavior during Head Start to children's kindergarten cognitive abilities. Child Development, 73, 110-131. doi:10.1111/1467 $-8624.00395$

Jelicic, H., Phelps, E., \& Lener, R. M. (2009). Use of missing data methods in longitudinal studies: The persistence of bad practices in developmental psychology. Developmental Psychology, 45, 1195-1199. doi:10.1037/a0015665

Kline, R. B. (2011). Principles and practice of structural equation modeling (3rd ed.). New York, NY: The Guilford Press.

Kochanska, G., Aksan, N., Penney, S. J., \& Doobay, A. F. (2007). Early positive emotionality as a heterogenous trait: Implications for children's self-regulation. Journal of Personality and Social Psychology, 93, 1054-1066. doi:10.1037/0022-3514.93.6.1054

Kochanska, G., Murray, K. T., \& Harlan, E. T. (2000). Effortful control in early childhood: Continuity and change, antecedents, and implications for social development. Developmental Psychology, 36, 220-232. doi:10.1037/0012-1649.36.2.220

Kochanska, G., Murray, K., Jacques, T. Y., Koenig, A. L., \& Vandegeest, K. A. (1996). Inhibitory control in young children and its role in emerging internalization. Child Development, 67, 490-507. doi:10.2307/1131828

Kurdek, L. A., \& Sinclair, R. J. (2000). Psychological, family, and peer predictors of academic outcomes in first-through fifth-grade children. Journal of Educational Psychology, 92, 449457. doi:10.1037/0022-0663.92.3.449 
Kurdek, L. A., \& Sinclair, R. J. (2001). Predicting reading and mathematics achievement in fourth-grade children from kindergarten readiness scores. Journal of Educational Psychology, 93, 451-455. doi:10.1037/0022-0663.93.3.451

Ladd, G.W. (2004). Probing the adaptive significance of children's behavior and relationships in the school context: A child by environment perspective. Advances in Child Behavior and Development, 31, 43-104. doi:10.1016/s0065-2407(03)31002-х

Laranjo, J., \& Bernier, A. (2013). Children's expressive language in early toddlerhood: Links to prior maternal mind-mindedness. Early Child Development and Care, 183, 951-962. doi:10.1080/03004430.2012.699964

Laranjo, J., Bernier, A., \& Meins, E. (2008). Associations between maternal mind-mindedness and infant attachment security: Investigating the mediating role of maternal sensitivity. Infant Behavior and Development, 31, 688-695. doi:10.1016/j.infbeh.2008.04.008

La Paro, K. M., \& Pianta, R. C. (2000). Predicting children's competence in the early school years: A meta-analytic review. Review of Educational Research, 70, 443-484. doi:10.3102 $/ 00346543070004443$

Lemelin, J. P., Boivin, M., Forget-Dubois, N., Dionne, G., Séguin, J. R., Brendgen, M., ... Pérusse, D. (2007). The genetic-environmental etiology of cognitive school readiness and later academic achievement in early childhood. Child Development, 78, 1855-1869. doi:10.1111/j.1467-8624.2007.01103.x

Leerkes, E. M., Blankson, A. N., O'Brien, M., Calkins, S. D., \& Marcovitch, S. (2011). The relation of maternal emotional and cognitive support during problem solving to pre-academic skills in preschoolers. Infant and Child Development, 20, 353-370. doi:10.1002/icd.728

MacKinnon, D. P. (2008). Introduction to statistical mediation analysis. Mahwah, NJ: Erlbaum. 
MacKinnon, D. P., Lockwood, C. M., Hoffman, J. M., West, S. G., \& Sheets, V. (2002). A comparison of methods to test mediation and other intervening variable effects. Psychological Methods, 7, 83-104. doi:10.1037/1082-989X.7.1.83

Matte-Gagné, C., \& Bernier, A. (2011). Prospective relations between maternal autonomy support and child executive functioning: Investigating the mediating role of child language ability. Journal of Experimental Child Psychology, 110, 611-625. doi:10.1016/j.jecp.2011 .06 .006

Meador, K. J., Baker, G. A., Browning, N., Clayton-Smith, J., Cohen, M. J., Kalayjian, L. A., ... \& Loring, D. W. (2011). Relationship of child IQ to parental IQ and education in children with fetal antiepileptic drug exposure. Epilepsy \& Behavior, 21, 147-152. doi:10.1016 /j.yebeh.2011.03.020

Meins, E. (1997). Security of attachment and the social development of cognition. Hove, UK: Psychology Press.

Meins, E., \& Fernyhough, C. (1999). Linguistic acquisitional style and mentalising development: The role of maternal mind-mindedness. Cognitive Development, 14, 363-380. doi:10.1016 /s0885-2014(99)00010-6

Meins, E., \& Fernyhough, C. (2010). Mind-mindedness coding manual, Version 2.0. Unpublished manuscript. Durham University, Durham, UK.

Meins, E., Fernyhough, C., Arnott, B., Leekam, S. R., \& de Rosnay, M. (2013). Mindmindedness and theory of mind: Mediating roles of language and perspectival symbolic play. Child Development, 84, 1777-1790. doi:10.1111/cdev.12061 
Meins, E., Fernyhough, C., Fradley, E., \& Tuckey, M. (2001). Rethinking maternal sensitivity: Mothers' comments on infants' mental processes predict security of attachment at 12 months. Journal of Child Psychology and Psychiatry, 42, 637-648. doi:10.1111/1469-7610.00759

Meins, E., Fernyhough, C., Wainwright, R., Clark-Carter, D., Das Gupta, M., Fradley, E., \& Tuckey, M. (2003). Pathways to understanding mind: Constructs validity and predictive validity of maternal mind-mindedness. Child Development, 74, 1194-1211. doi: $10.1111 / 1467-8624.00601$

Merz, E. C., Landry, S. H., Williams, J. M., Barnes, M. A., Eisenberg, N., Spinrad, T. L., ... Clancy-Menchetti, J. (2014). Associations among parental education, home environment quality, effortful control, and preacademic knowledge. Journal of Applied Developmental Psychology, 35, 304-315. doi:10.1016/j.appdev.2014.04.002

Meuwissen, A. S., \& Carlson, S. M. (2015). Fathers matter: The role of father parenting in preschoolers' executive function development. Journal of Experimental Child Psychology, 140, 1-15. doi:10.1016/j.jecp.2015.06.010

Mistry, R. S., Benner, A. D., Biesanz, J. C., Clark, S. L., \& Howes, C. (2010). Family and social risk, and parental investments during the early childhood years as predictors of low-income children's school readiness outcomes. Early Childhood Research Quarterly, 25, 432-449. doi:10.1016/j.ecresq.2010.01.002

Morgan, P. L., Farkas, G., Hillemeier, M. M., Hammer, C. S., \& Maczuga, S. (2015). 24-monthold children with larger oral vocabularies display greater academic and behavioral functioning at kindergarten entry. Child Development, 86, 1351-1370. doi:10.1111/cdev.12398 
NICHD Early Child Care Research Network (2003). Do children's attention processes mediate the link between family predictors and school readiness? Developmental Psychology, 39, 581593. doi:10.1037/0012-1649.39.3.581

Nordling, J. K., Boldt, L. J., O'Bleness, J., \& Kochanska, G. (2016). Effortful control mediates relations between children's attachment security and their regard for rules of conduct. Social Development, 25, 268-284. doi:10.1111/sode.12139

Nurss, J., \& McGauvran, M. (1995). Metropolitan Readiness Tests—Sixth edition (MRT6). San Antonio, TX: Psychological Corporation.

Parker, F. L., Boak, A. Y., Griffin, K. W., Ripple, C., \& Peay, L. (1999). Parent-child relationship, home learning environment, and school readiness. School Psychology Review, 28, 413-425. Retrieved from http://search.proquest.com/openview /38564c5085c1b1fce8866112bdc0cfd2/1?pq-origsite=gscholar

Pederson, D. R., \& Moran, G. (1995). A categorical description of infant-mother relationships in the home and its relation to Q-sort measures of infant-mother interaction. Monographs of the Society for Research in Child Development, 60, 111-132. doi:10.1111/j.1540-5834.1995 .tb00207.x

Preacher, K. J., \& Hayes, A. F. (2008). Asymptotic and resampling strategies for assessing and comparing indirect effects in multiple mediator models. Behavior Research Methods, 40, 879891. doi:10.3758/BRM.40.3.879

Razza, R. A., Martin, A., \& Brooks-Gunn, J. (2010). Associations among family environment, sustained attention, and school readiness for low-income children. Developmental Psychology, 46, 1528-1542. doi:10.1037/a0020389 
Rothbart, M. K., \& Bates, J. E. (2006). Temperament. In W. Damon (Series Ed.) \& N. Eisenberg (Vol. Ed.), Handbook of child psychology: Vol. 3. Social, emotional, personality development (6th ed., pp. 99-166). New York, NY: Wiley.

Rothbart, M., \& Jones, L. (1998). Temperament, self-regulation, and education. School Psychology Review, 27, 479-491. Retrieved from http://search.proquest.com/openview /26bace8e5cb1393e03c3e05e26c3abed/1?pq-origsite=gscholar

Rowe, M. L. (2008). Child-directed speech: Relation to socioeconomic status, knowledge of child development and child vocabulary skill. Journal of Child Language, 35, 185-205. doi:10.1017/s0305000907008343

Sameroff, A. J., \& Haith, M. M. (1996). The five to seven year shift: The age of reason and responsibility. Chicago, IL: University of Chicago Press.

Scarpati, S., \& Silver, P. G. (1999). Readiness for academic achievement in preschool children.

In E. V. Nuttall, I. Romero, \& J. Kalesnik (Eds.), Assessing and screening preschoolers: Psychological and educational dimensions (pp. 262-280). Boston, MA: Allyn \& Bacon.

Schafer, J. L. (1997). Analysis of incomplete multivariate data. London, UK: Chapman \& Hall.

Schofield, H. T., Bierman, K. L., Heinrichs, B., \& Nix, R. L. (2008). Predicting early sexual activity with behavior problems exhibited at school entry and in early adolescence. Journal of Abnormal Child Psychology, 36, 1175-1188. doi:10.1007/s10802-008-9252-6

Shai, D., \& Belsky, J. (2011). When words just won’t do: Introducing parental embodied mentalizing. Child Development Perspectives, 5, 173-180. doi: 10.1111/j.17508606.2011.00181.x

Strommen, E. A. (1973). Verbal self-regulation in a children's game: Impulsive errors on "Simon Says". Child Development, 44, 849-853. doi:10.2307/1127737 
Tabachnick, B. G., \& Fidell, L. S. (2013). Using multivariate statistics (6th ed.). Boston, MA: Pearson Education.

Tamis-LeMonda, C. S., \& Rodriguez, E. T. (2008). Parents' role in fostering young children's learning and language development. In R. E. Tremblay, R. G. Barr, \& R. V. Peters (Eds.), Encyclopedia on early childhood development (pp. 1-10). Montreal, QC: Centre of Excellence for Early Childhood Development.

Valiente, C., Lemery-Chalfant, K., \& Swanson, J. (2010). Prediction of kindergartners' academic achievement from their effortful control and emotionality: Evidence for direct and moderated relations. Journal of Educational Psychology, 102, 550-560. doi:10.1037/a0018992

Vallotton, C., \& Ayoub, C. (2011). Use your words: The role of language in the development of toddlers' self-regulation. Early Childhood Research Quarterly, 26, 169-181. doi:10.1016 /j.ecresq.2010.09.002

Van IJzendoorn, M. H., Vereijken, C. M. J. L., Bakermans-Kranenburg, M. J., \& RiksenWalraven, J. M. (2004). Assessing attachment security with the attachment Q-sort: Metaanalytic evidence for the validity of the observer AQS. Child Development, 75, 1188-1213. doi:10.1111/j.1467-8624.2004.00733.x

Venet, M., Normandeau, S., Letarte, M.-J., \& Bigras, M. (2003). Les propriétés psychométriques du Lollipop [Psychometric properties of the Lollipop]. Revue de Psychoéducation, 32, 165176. Retrieved from http://cat.inist.fr/?aModele=afficheN\&cpsidt=14878009

Winsler, A., Diaz, R. M., McCarthy, E. M., Atencio, D. J., \& Chabay, L. A. (1999). Motherchild interaction, private speech, and task performance in preschool children with behavior problems. Journal of Child Psychology and Psychiatry, 40, 891-904. doi:10.1111/14697610.00507 


\section{Footnote}

${ }^{1}$ This composite score of effortful control was more strongly related to other variables in the model than any single task score. 
Table 1

Mean, Standard Deviation, and Range for Key Study Variables

\begin{tabular}{lccc}
\hline Variable & Mean & Standard deviation & Observed range \\
\hline Maternal mind-mindedness & 14.64 & 8.11 & $0-40$ \\
Child language at age 2 & 59.34 & 22.66 & $3-98$ \\
Effortful control at age 3 & 83.08 & 22.22 & $5-95$ \\
Effortful control at age 4 & -0.01 & 1.02 & $-3.68-2.31$ \\
School readiness at age 5 & 62.63 & 6.65 & $16-69$ \\
\hline
\end{tabular}


Table 2

Inter-Correlations among Study Variables

\begin{tabular}{|c|c|c|c|c|c|c|c|c|}
\hline & 2. & 3. & 4. & 5. & 6. & 7. & 8. & 9. \\
\hline 1. Maternal mind-mindedness & $.21 * *$ & $.16^{*}$ & $.22 * *$ & $.20 *$ & .10 & $.20 * *$ & .09 & $.19 * *$ \\
\hline 2. Child language at age 2 & 1.00 & $.27 * * *$ & $.18^{*}$ & $.19 *$ & $.16^{*}$ & $.21 * *$ & $.27 * * *$ & $.18^{*}$ \\
\hline 3. Effortful control at age 3 & & 1.00 & $.35 * * *$ & .07 & .03 & $.17 *$ & $.19 * *$ & .11 \\
\hline 4. Effortful control at age 4 & & & 1.00 & $.35 * * *$ & .10 & $.20 * *$ & $.21 * *$ & $.21 * *$ \\
\hline 5. School readiness at age 5 & & & & 1.00 & $.19 *$ & $.32 * * *$ & .12 & .12 \\
\hline 6. Child sex & & & & & 1.00 & -.08 & -.01 & -.02 \\
\hline 7. Family SES & & & & & & 1.00 & $.26 * * *$ & $.28 * * *$ \\
\hline 8. Child initial cognition & & & & & & & 1.00 & $.29 * * *$ \\
\hline 9. Maternal sensitivity & & & & & & & & 1.00 \\
\hline
\end{tabular}

Note. Child sex is coded: 1 = boy; 2 = girl. SES = socio-economic status. Child initial cognition = child initial cognitive performance as indexed by the Mental Development Index of the Bayley Scales of Infant Development.

$* p<.05 . * * p<.01 . * * * p<.001$. 


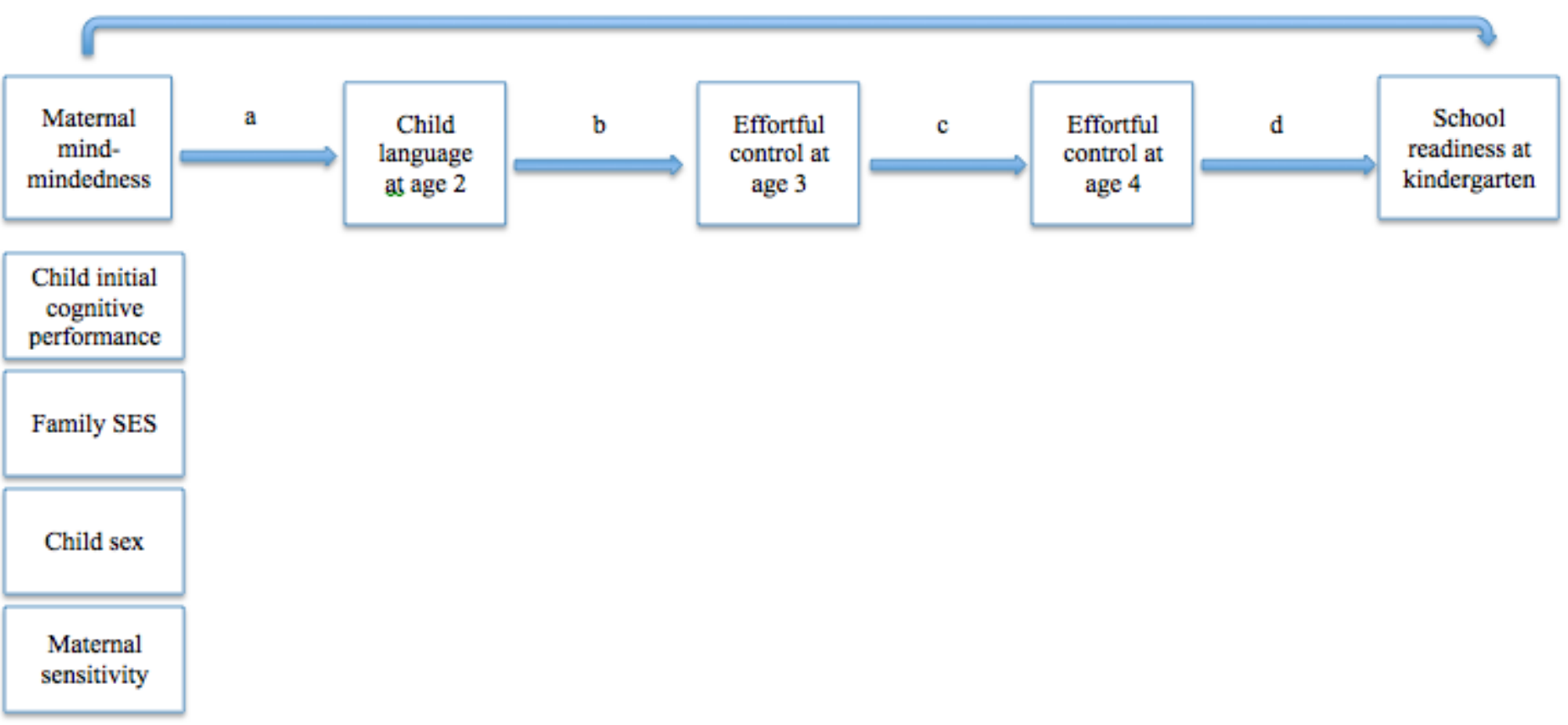

Figure 1. Proposed theoretical model. Variables displayed below maternal mind-mindedness are covariates. 
$\mathrm{e}=.05, p=.489$

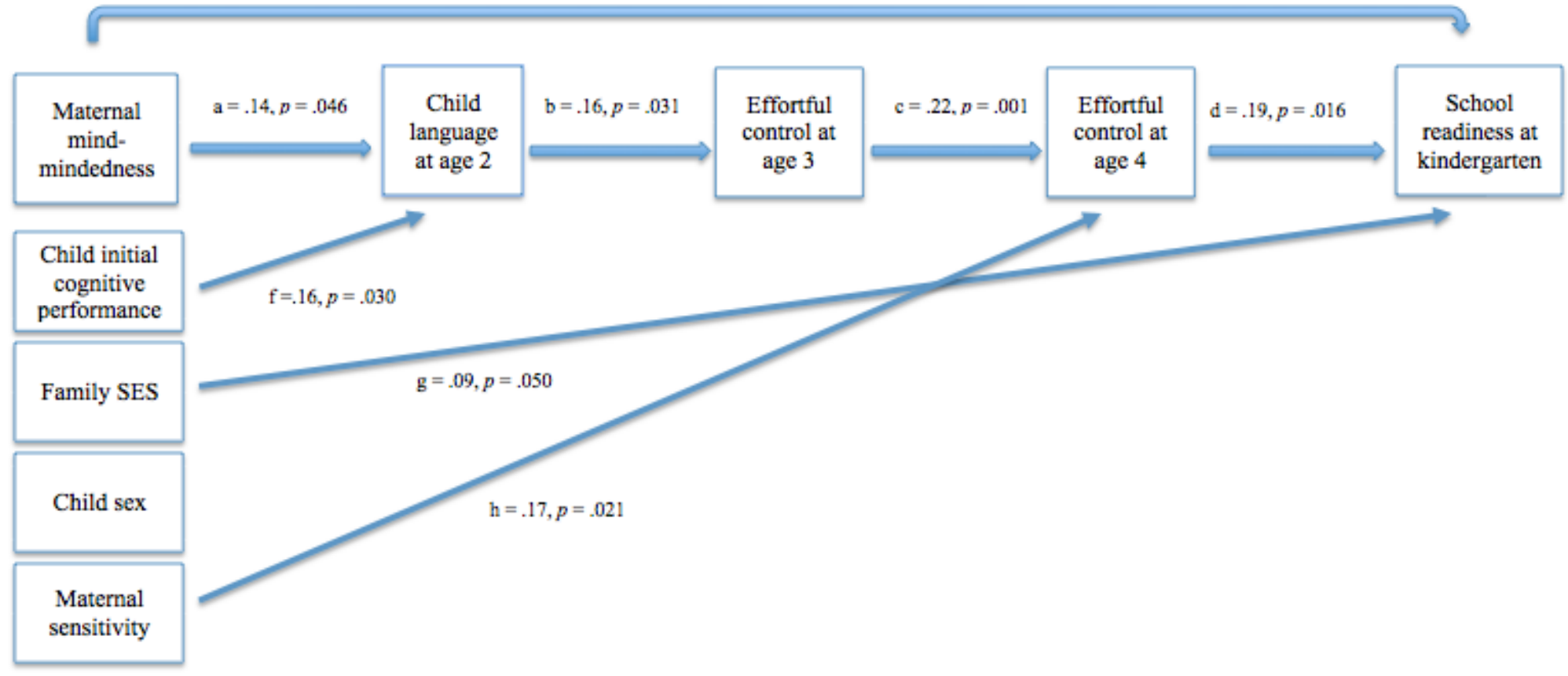

Figure 2. Final model. Only significant paths $(p \leq .05)$ are displayed. 